\title{
Effect of handwashing with soap at crtitical times and home based water treatment in combating hot spot areas of childhood diarrhea in Ethiopia
}

Bezuayehu Alemayehu ( $\sim$ bezua@ymail.com )

Jimma University College of Public Health and Medical Sciences https://orcid.org/0000-0002-41260939

\section{Argaw Ambleu}

Jimma Institute of Health Sciences: Jimma University

Birhanu Teshome Ayele

Stellenbosch University

\section{Research}

Keywords: Childhood diarrhea, handwashing, Home-based water treatment, RCT

Posted Date: February 23rd, 2021

DOI: https://doi.org/10.21203/rs.3.rs-212508/v1

License: (a) (1) This work is licensed under a Creative Commons Attribution 4.0 International License. Read Full License 


\section{Abstract}

Introduction

Effective intervention needed to reduce childhood diarrhea, a significant cause of morbidityin resourcelimited settings. This intervention aimed to evaluate the effectiveness of handwashing with soap at critical times, home-based water treatment and both combinations to reduce childhood diarrheain hotspot areas of southwestern Ethiopia.

\section{Methods}

Community randomized control with the factorial design was conducted in southwestern Ethiopia from July to October $30 / 2020$. About 720 households were maintained and equally allocated for handwashing with soap at critical times, home-based water treatment, and both combined interventions having 180 households that were followed up for four months. Baseline data were collected at the first two weeks from 720 households of intervention groups. Data was processed and entered into EPI data version 3.02. Homogeneity of the baseline characteristics of the participant in both groups was checked at a p-value less or equal to 0.05 . The incidence of childhood diarrhea per 100 per two weeks was measured in both groups. Mann-Kendall trend test was performed to check the statistical significance patterns of childhood diarrhea. Intention-to-treat analysis was used to compare the incidence of childhood diarrhea for both groups. A generalized estimating equation with a logit-link Poisson distribution family and the exchangeable working correlation,with robust standard error estimation, was used for the analysis of repeated observations of the incidence of childhood diarrhea in individuals over time. An unadjusted and adjusted incidence rate along with the corresponding $95 \% \mathrm{Cl}$ was analyzed by using a multivariable analysis to control potential confounders on Stata 14 software.

Results

Childhood diarrhea significantly decreased in all intervention groupsbut increasing in control groups. Particularly, handwashing with soap at critical times has reduced childhood diarrhea incidence by $45 \%$ (IRR $=0.55,0.48,0.61, \mathrm{P}<0.001)$. Similarly,home-based water treatment reduced by $52 \%(\mathrm{IRR}=0.48,0.42$, $0.54, P<0.001)$. Likewise, a combination of handwashing with soap and home-based water treatment has reduced childhood diarrhea by $60 \%(A O R=0.40,0.36,0.47, \mathrm{P}<0.001)$ after adjusting potential confounders.

Conclusion

This study indicated single and combined interventions reduced childhood diarrhea. Promoting these effective or promising intervention effects in rural communities would save many lives of children from diarrhea.

Trial registration 


\section{Introduction}

Childhood diarrhea (CHD hereafter) is caused by enteric pathogenic bacteria, viruses, and parasites [1, 2]. CHD remains a major public health threat with nearly 1.7 billion cases occurring annually in the second for 578,000 deaths[3]. CHD spreads from person to person, aggravated by poor personal hygiene [4] and poor quality of water, sanitation and hygiene that account for 1.7 million deaths, with a significant majority of deaths in developing countries [5].

Global estimates of deaths from CHD have shown a decline from 2.5 million in 2000 to 1.4 million in 2010 [6] which is still spread all over the world, especially in developing regions such as Africa, South East Asia, and the Eastern Mediterranean, where there is rapid population growth, increased urbanization, limited infrastructures and health system $[2,7]$. While mortality rate declined globally but in Africa,the region is seven times higher than that in the European region $[8,9]$. Althoughmortality attributed to $\mathrm{CHD}$ has decreased significantly over the past 15 years, the morbidity has changed little, but in 2013,578,000 died from CHD [10], 54\% of these deaths were in Sub-Saharan and 25\% in Nigeria [11, 12], that the third leading cause of death in children in Ghana[13].

However, in Ethiopia, annually, CHD kills half a million children next to pneumonia that affected by poor sanitation, shortage of clean water supply and poor personal hygiene, responsible for $90 \%$ of CHD occurrence [14]. The 2011 Demographic and Health Survey Ethiopia (EDHS) findings showed that $13 \%$ of the children had a CHD in two weeks including South Nation Nationality and People Region (SNNPR) [15]. The proportion of CHD morbidity in Ethiopia is about $22.6 \%$ in the different regions with a median of $45 \%$. Similarly, in the northwest parts of Ethiopia, the annual incidence rate was 155.3 per 1,000 populations at risk with varied greatly across the study districts [16]. The previous study in this study area reported that socio economic and environmental factors contributed CHD in Sheko district, Bench Maji Zone, southwest Ethiopia [17]. Additionally this study area is noticed as a CHD hotspot areas due to multiple factors that need due attentions (Fig. 1).

To curve the burden of CHD, improvements in water, sanitation, and hygiene have been considered key public health interventions in low- and middle-income countries [18]. Among various interventions of CHD, handwashing is the simplest and most effective way to prevent diarrhea on under five children [19]. Mainly, hand wash with soap has significant effects on CHDthat reduce by $42-47 \%$ [20].The level of CHD risk is too variable like higher among children whose mothers did not wash hand with soap before food preparation, feeding and after leaving the toilet [21].Moreover, hygiene interventions, particularly the provision of soap for handwashing, effectively reduce diarrhea morbidity, and there does not appear to be evidence that compliance falls over time.

A study revealed that the prevalence of CHD was $18.3 \%$ that is affected by individual and community level factors, summarized as the following, not washing hands during critical times were 4.6 times risk for $\mathrm{CHD}$ while sharing the same residence with domestic animals were 2.87 times more at risk for CHD. 
Particularly obtaining drinking water from unimproved sources was 2.53 times riskier for CHD. In addition, mothers with limited knowledge about diarrhea were $76 \%$ less likely at risk for CHD, and starting supplementary child feeding at age less than six months were $35 \%$ less likely risky for $\mathrm{CHD}$ [22]. This factor implies multiple interventions are required to prevent $\mathrm{CHD}$ with factorial design.

Several interventional studies were done like p-value a cluster randomized control trial in Pakistan on the effectiveness of handwashing promotion in CHD high-risk communities that decreased the incidence of diarrhea by $39 \%$ [23]. Similarly,WASH interventions showed CHD reductions between $27 \%$ and $53 \%$ among children [24]. In another study conducted in Dabat district northwestern Gonder, clusterrandomized control trial on the intervention of SODIS as a water treatment for household, diarrhea incidence decreased 40\% [25]. Similarly, at Jijiga district eastern Ethiopia community-based cluster randomized control trial on handwashing with soap and WASH education has decreased the incidence of $\mathrm{CHD}$ by $35 \%$ [26]. Moreover, mainly household water treatment has been recognized as a cost-effective means of reducing the burden of $\mathrm{CHD}$ and other waterborne diseases, especially among populations without access to improved water supplies [27], where strategies to improve the microbialquality of drinking water can be applied at the source or in the household. Water source includes protected wells, boreholes andpublic tap stands [28]. Whereas household strategies includeimproved water storage or approaches for treating water, such as chlorination,solar disinfection, filtration, or combined flocculation anddisinfection [24].

Despite the availabilities of few studies on interventions on CHD, there are no or limited evidence of handwashing with soap at a critical time and home-based water treatment at the household level in this study area. Additionally, combination effects the intereventions that aimed to control the prevailing burden of $\mathrm{CHD}$ through community randomized control trial(CRCT) also limited. Thus, the CRCT interventional trial was planned to significantly reduce the peaking of $\mathrm{CHD}$ in hotspot areas.

The rationale for designing the $\mathrm{CRCT}$ intervention is due to the CHD burden prevailing in southwest Ethiopia based on research findings and related empirical evidence [22]. As a result, we have found a high burden $(36.1$ per 1,000$)$ of CHD with significant variation between the districts in southwest Ethiopia.To respond to the CHD effects, the CRCT is claimed to be used to identify the cause-effect relation between the outcomes and reduced CHD burden. Mainly, avoid any population bias, easier to blind analyzed with well-known statistical tools; populations of participating individuals are identified in-group.

Evidence needed on all potential intervention measurements with handwashing intervention at a critical time, where the intervention households benefited directly with gain health education and soap for handwashing purpose to prevent the incidence of $\mathrm{CHD}$. Since the intervention is simple and costs usefull for all family members, specifically low-income countries like Ethiopia can apply the resultto preventCHD and other communicable diseases. Furthermore, it was used for concerned bodies, policymakers' executive/implementers and governmental or non-governmental bodies to focus on specific CHD prevention intervention and contribute to the future research hypothesis. Thus, this intervention aimed to 
evaluate the effectiveness of handwashing with soap at a critical time and home-based water treatment to CHD in hotspot areas of southwestern Ethiopia, 2020.

\section{Methods}

\section{Study setting and period}

The study was conducted in North Bench district, Bench Maji zone, southwestern Ethiopia, which is found $550 \mathrm{~km}$ from Addis Ababa, from February to July 30/2020. The projected populations are 148,285 of which 71,177 men and 77,108 women. The district has 24 kebeles with 29,610 households with an average family size of 4.14 persons (Fig. 2).

\section{Study design and sample size calculation}

A factorial community based clustered RCT was used to conduct an intervention in southwestern Ethiopia. The intervention households were selected randomly for RCT based on the established criteria. The sample size was determined based on the method developed by Hayes and Bennett [29] and using the following assumptions: 6.3 episodes/100 person week observation among control group from previous similar trials [26], 80\% statistical power, a 95\% confidence and considered both type I and type II errors. As per the guidelines of cluster-randomized trials in health service research, intracluster coefficient (ICC) is an appropriate way to estimate cluster variability and 0.02 was maintained. About 720 households were selected that expected to detect forty percent (40\%) difference in episodes between the intervention and control groups, including design effects of 1.38 [25]. Finally, 720 households have been equally allocated with a ratio of 1:1 for each arm. The study has four arms as households used only handwashing with soap at a critical time, households provided Wuha Agar ( a solution used for water treatment) for home-based water treatment, both combinations of handwashing with soap at six critical times and home-based water treatment, and control, which have no any intervention activity.

\section{Participants eligibility criteria}

Baseline characteristics of households $(\mathrm{HH})$ with children were assessed before the intervention. The baseline data included $\mathrm{HH}$ characteristics (socioeconomic and WASH status), child status (age, gender, vaccine status, time for supplementary feeding). Oral informed consent was obtained from the mother/caregivers of the selected child. A household was considered eligible if the following criteria are met: 1) least one child aged 0-59 months living in the home, 2) not being a model household, (households that successfully implement all 16 packages of the Health Extension Program (HEP) are officially certified as a model health extension household, 3) mothers/caregivers of U5 children living in the study area for at least four months and have no plan of migrating during the study period, 4) the children was excluded, when they are seriously sick by an other disease at the time of study and are referred to a near health facility, 5)the communitiesusing only untreated drinking-water sources, 6) unavailability of drinking water-quality management and diarrhea intervention programs in the community. 


\section{Randomization process and masking}

A randomization process was done to address the targeted children in both groups. The proportions of the households were1:1 ratio for groups and 720 households with under-five children were randomized and followed for four months (Fig. 3).

The North Bench district was among the hotspot areas of CHD selected using the lottery method that have 29610 households. About 720 households were selected based on the eligibility criteria. The purpose of the study did not inform field workers and the study participant. The randomization was performed based on CONSORT(Consolidated Standards of Reporting Trials) statement flow chart designed to conduct effective randomization such as enrollment of participants, allocations of intervention, following up and analysis from the trial (Fig. 3).

\section{Intervention approaches}

Interventions were given after preparing an activity protocol designed to prevent $\mathrm{CHD}$ at the $\mathrm{HH}$ level. The intervention activity was a key message that was provided to eligible HHs bi-weekly for the next four months after a practical demonstration and providing key health messages at theindividual $\mathrm{HH}$ level by assigning fieldworkers. Identical Plain soap, Wuha agar, and both plain soap and Wuha agarwere provided for eligible HHs after an active demonstration. Printing materials (leaflets) were prepared in Amharic stating six critical times of HW with key messages. Pictorial depiction of the critical times was provided for those who could not read print materials. The message was reinforced every two weeks of visiting, one bar of soap and one bottle of Wuha agarwas provided to the families in the intervention $\mathrm{HHs}$. In contrast, in the control HHs there is no interventions provide for the prevention of CHD, but the field workers collect and record the incidences of diarrhea every two weeks for four months.Impression materials (leaflets) were prepared with critical messages in Amharic statingthe critical HW time and amount of WuhaAgarfor water treatment. The pictorial representation of the critical times and water treatment for those unable to read printed materials were provided. The message was enforced every two weeks of stay, and the families were supplied with one bar of soap and Wuha agar for respective HHs. There is no intervention for the control groups to minimize the incidence of diarrhea. Field workers were collected, recorded the incidence, managed the case for the consecutive four months, and reported the incidence of diarrhea every two weeks. The intervention was undertaken based on intervention modalitysuch as washing hands with soap at six critical times (demonstrated \& health educations give), using 20 liter jerry can or pot to treat the water with Wuha agar solution, providing key messages on CHD meaning, ways of transmission, methods of prevention and controlling diarrhea at $\mathrm{HH}$ level through $\mathrm{HW}$.

\section{Data collection and outcome assessment}

Assigned field workers from June 15-30 /2020, collected the baseline data. At each visit, the fieldworker was collecting data of incidence Diarrhea happen on under-five children from the mother/caregiver of the child. The primary outcome was the incidence of diarrhea, from both receiving the intervention and control groups. CHD data were recorded and following the recommended standard definition of diarrhea 
[2]. The primary caretakers were instructed to follow and report the occurrence of diarrhea within two weeks.CHD is defined as the passage of the loose or watery stool at least three or more times in a day occurring and recorded for both intervention and control groups [2].

\section{Follow up and data management}

The questionnaire was initially prepared in the English language and then, it was translated into Amharic and then back to English language-by-language Experts to check the consistency. Data collectors were selected based on their experience and willingness then, three days of training was given separately on the data collection format, procedure, and demonstration for intervention and control groups. Supervisors were assigned and monitor the data collection process. The collected data were checked for accuracy, consistency, and completeness. Any missed or incomplete data of response was correct at the time of data collection day. Close follow up was done with field workers for four months. Upon closing the intervention, data were cross-cheeked by supervisors and baseline and follow-up visit data forms was checked for completeness and consistency.

\section{Statistical analysis}

Data was entered into EPI data version 3.02 and exported to StataSE14 software for statistical analysis. Intention-to-treat analysis was used to compare the incidence of $\mathrm{CHD}$ for intervention and control groups. The baseline data was analyzed to check the homogeneity of both study groups, such as continuous variables with non-normal distribution were reported as medians (IQRs), and tested with Fisher's exact test and discrete variableswere presented as percentages. The incidence of CHD (IRR) (per 100 persontwo weeks) children was measured for the intervention and control groups. Mann-Kendall trend test was performed to check the statistical significance of whether the incidence of $\mathrm{CHD}$ increase, decrease, or constant during the intervention period. Generalized Estimating Equation (GEE) with a log-link Poisson distribution family and the exchange working correlation, with robust standard error estimation, was used for the analysis of repeated observations of CHD incidence in individuals over time to consider the clustered nature of the data. The unadjusted and adjusted incidence rate ratio (IRR) along with the corresponding $95 \%$ confidence intervals $(\mathrm{Cl})$ was analyzed by using a multivariable analysis to address or control potential confounders $[25,30]$.

\section{Results}

\section{The baseline characteristics of the participants}

The baseline characteristics of the study participants were presented in the following consecutive tables (Table 1). Baseline assessments of 720 households from four groups were interviewed before the actual intervention on June $16-30,2020$. The median age of the caretakers was $33 \pm 4.93,34 \pm 6,33 \pm 5.14$, and $33 \pm 4.3$ for the control, hand washing, home-based water treatment, and both combined groups, respectively. The $p$-value revealed there is no significant difference between control and treatment groups in terms of socioeconomic variables. 
Table 1

Baseline characteristics of the study participants

\begin{tabular}{|c|c|c|c|c|c|}
\hline \multirow[t]{4}{*}{ Variables } & \multicolumn{5}{|c|}{ Study participants $(n=180, N=720)$} \\
\hline & \multirow{3}{*}{$\begin{array}{l}\text { Control } \\
F(\%)\end{array}$} & \multirow{3}{*}{$\begin{array}{l}\text { Hand } \\
\text { washing } \\
\mathrm{F}(\%)\end{array}$} & \multirow{3}{*}{$\begin{array}{l}\text { Home-based water } \\
\text { treatment } \\
\mathrm{F}(\%)\end{array}$} & \multirow{3}{*}{$\begin{array}{l}\text { Combined } \\
F(\%)\end{array}$} & \multirow{3}{*}{$\begin{array}{l}\mathrm{p}- \\
\text { value }\end{array}$} \\
\hline & & & & & \\
\hline & & & & & \\
\hline $\begin{array}{l}\text { Age of care } \\
\text { givers(Median + SD) }\end{array}$ & $33 \pm 4.93$ & $34 \pm 6$ & $33 \pm 5.14$ & $33 \pm 4.3$ & 0.134 \\
\hline $\begin{array}{l}\text { Mean family size (Median } \\
+ \text { SD) }\end{array}$ & $4 \pm 0.75$ & $3 \pm 0.76$ & $4 \pm 0.87$ & $3 \pm 0.96$ & 0.075 \\
\hline $\begin{array}{l}\text { The education level of } \\
\text { caregiver }\end{array}$ & & & & & 0.053 \\
\hline No formal education & $73(40.6)$ & $91(50.6)$ & $100(56.6)$ & $82(45.6)$ & \\
\hline Primary education & $72(40)$ & $54(30)$ & $52(28.9)$ & $72(40)$ & \\
\hline $\begin{array}{l}\text { More than secondary } \\
\text { education }\end{array}$ & $35(19)$ & $31(17.2)$ & $28(15.6)$ & $35(19.4)$ & \\
\hline $\begin{array}{l}\text { Mothers/caregivers' } \\
\text { occupation }\end{array}$ & & & & & 0.076 \\
\hline Farmer & $40(22.2)$ & $39(21.7)$ & $39(21.70$ & $33(18.3)$ & \\
\hline Merchant & $24(13.3)$ & $26(14.4)$ & $27(15)$ & $25(13.9)$ & \\
\hline Student & $23(12.8)$ & $25(13.9)$ & $32(17.8)$ & $25(13.9)$ & \\
\hline Government employee & $7(3.90$ & $6(3.3)$ & $10(5.6)$ & $22(12.2)$ & \\
\hline House wife & $86(47.8)$ & $84(46.7)$ & $82(45.6)$ & $75(41.7)$ & \\
\hline
\end{tabular}

\section{Drinking water supply among the study participants}

Table 2 indicates drinking water sources, the average time to fetch water in a minute, water storage container, water storage washing frequency, average water users per individual per day per litter, water drown and mean distance from the latrine to home were not significantly different among all study groups. 
Table 2

Drinking water supply among the study participants

\begin{tabular}{|c|c|c|c|c|c|c|}
\hline \multirow[t]{3}{*}{ Variables } & & \multicolumn{5}{|c|}{ Study participants $(n=180, N=720)$} \\
\hline & & \multirow{2}{*}{$\begin{array}{l}\text { Control } \\
F(\%)\end{array}$} & \multirow{2}{*}{$\begin{array}{l}\text { Hand } \\
\text { washing } \\
\text { F (\%) }\end{array}$} & \multirow{2}{*}{$\begin{array}{l}\text { Home-based } \\
\text { water treatment } \\
\text { F (\%) }\end{array}$} & \multirow{2}{*}{$\begin{array}{l}\text { Combined } \\
F(\%)\end{array}$} & \multirow{2}{*}{$\begin{array}{l}\mathrm{P} \text { - } \\
\text { value }\end{array}$} \\
\hline & & & & & & \\
\hline \multicolumn{6}{|c|}{ Drinking water sources } & \multirow[t]{4}{*}{0.307} \\
\hline \multicolumn{2}{|l|}{ Protected spring } & 151(83.9) & $138(76.7)$ & 154(85.6) & $148(82.2)$ & \\
\hline \multicolumn{2}{|l|}{ Unprotected spring } & $21(11.7)$ & $25(13.9)$ & $18(10)$ & $20(11.1)$ & \\
\hline \multicolumn{2}{|l|}{ River } & $17(9.4)$ & $8(4.4)$ & $8(4.4)$ & $12(6.7)$ & \\
\hline \multicolumn{2}{|l|}{$\begin{array}{l}\text { Time to fetch water } \\
\text { minute(Median + SD) }\end{array}$} & $26 \pm 4.98$ & $20 \pm 5.67$ & $25 \pm 54$ & $26 \pm 6.54$ & 0.646 \\
\hline \multirow{3}{*}{$\begin{array}{l}\text { Water storage } \\
\text { container }\end{array}$} & Jerry can & $110(61.1)$ & 128(71.1) & $116(64.4)$ & $125(69.4)$ & \multirow[t]{3}{*}{0.110} \\
\hline & Clay pot & $10(5.6)$ & 0 & $6(3.3)$ & $6(3.3)$ & \\
\hline & $\begin{array}{l}\text { Plastic } \\
\text { bucket }\end{array}$ & $60(33.3)$ & $52(28.9)$ & $58(32.3)$ & $49(27.2)$ & \\
\hline \multirow[t]{3}{*}{$\begin{array}{l}\text { Water storage } \\
\text { washing frequency }\end{array}$} & $\begin{array}{l}\text { Every } \\
\text { day }\end{array}$ & 129(71.7) & 118(56.6) & $111(61.7)$ & 128(71.1) & \multirow[t]{3}{*}{0.131} \\
\hline & $\begin{array}{l}\text { Once a } \\
\text { week }\end{array}$ & $35(19.4)$ & $39(21.7)$ & $40(22.2)$ & $39(21.7)$ & \\
\hline & $\begin{array}{l}\text { Twice a } \\
\text { week }\end{array}$ & $16(8.9)$ & $23(12.8)$ & $29(16.1)$ & $13(7.2)$ & \\
\hline \multicolumn{2}{|c|}{ water use p/c/d (Median + SD) } & $12 \pm 1.40$ & $12 \pm 1.22$ & $15 \pm 3.22$ & $15 \pm 1.52$ & 0.106 \\
\hline \multirow[t]{2}{*}{ Water drowns } & Dipping & 65 & 62 & 72 & 82 & \multirow[t]{2}{*}{0.126} \\
\hline & Pouring & 115 & 118 & 106 & 98 & \\
\hline \multicolumn{2}{|c|}{$\begin{array}{l}\text { Distance from latrine to } \\
\text { home(Median + SD) }\end{array}$} & $4 \pm 0.39$ & $4 \pm 0.66$ & $4 \pm 0.28$ & $4 \pm 0.74$ & 0.088 \\
\hline
\end{tabular}

\section{Children characteristics and handwashing practices of the participants}

Table 3 indicates there is no significant difference in study groups,like a number of children per household, caregiverawarenesson handwashing, handwashing practices at critical times, and COVID- 
$19 \mathrm{knowledge}$ and prevention practices.

Table 3

Children characteristics and handwashing practices of the participants

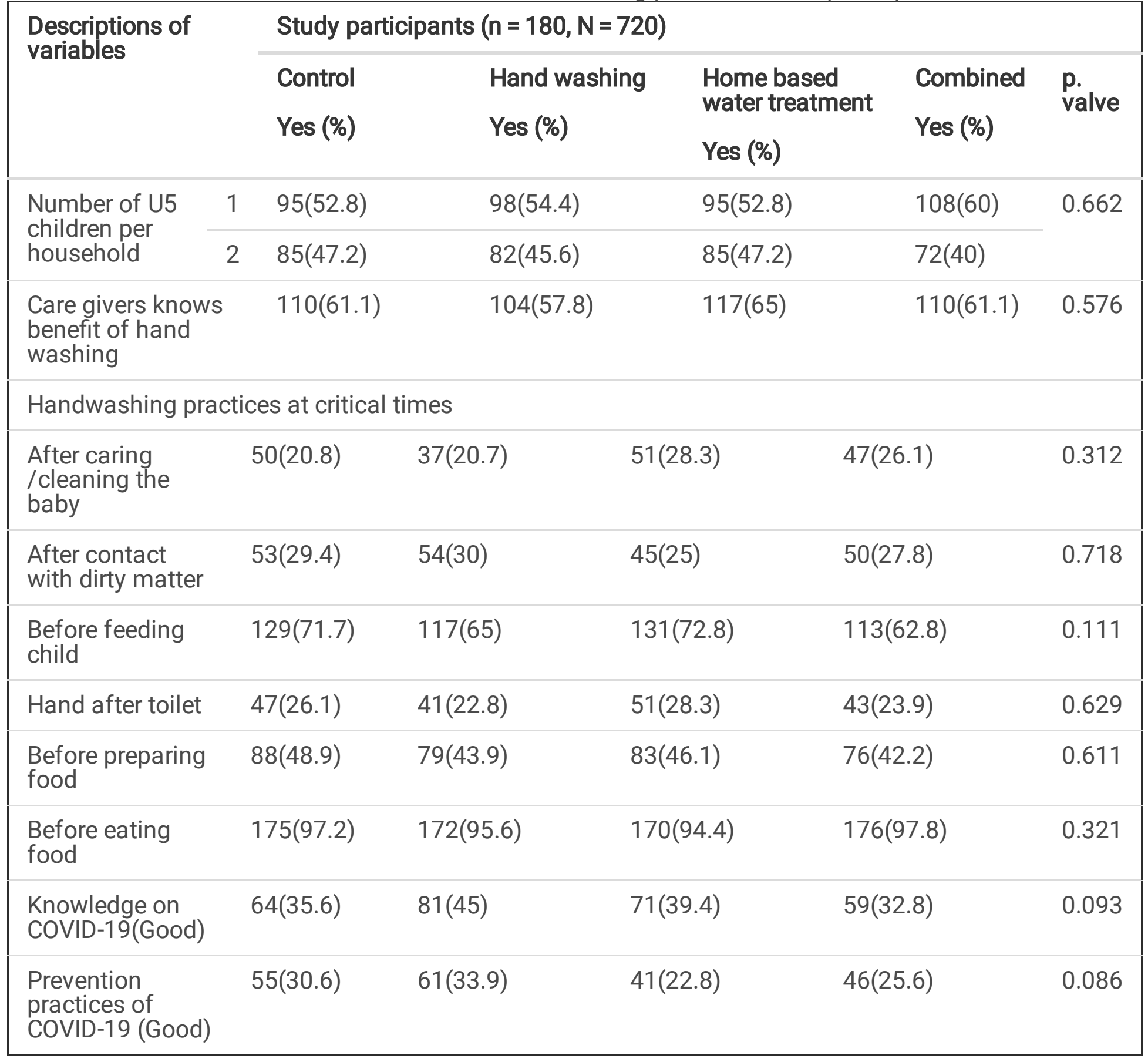

\section{Incidence of childhood diarrhea during the intervention}

Figure 4 indicates the incidence of CHDbi-weekly versus weeks of observation. There is a statistically significant decrease of incidence of $\mathrm{CHD}$ among handwashing with soap,home-based water treated, and in both combined groups, however, there is a statistically significant increasing trend in the incidence of CHD among control households. 


\section{Multivariable analysis of the effects of interventions on CHD}

Table 3 shows the multivariable analysis of the effects of the intervention on CHD. Children age greater than 6 months was $60 \%$ (AIR $=40,0.33,0.50, p<0.001)$ likely have developed diarrhea than the children age less than 6 months. Those households with no handwashingfacilities were $62 \%$ (IRR $=0.38,0.40$, $0.42, \mathrm{P}<0.001$ ) likely at risk of CHD than those with their counterparts did. Similarly, households consuming water less than $20 \mathrm{l} / \mathrm{c} / \mathrm{d}$ were $28 \%$ at risk for $\mathrm{CHD}$ compared with households using more than $20 \mathrm{l} / \mathrm{c} / \mathrm{d}(\mathrm{IRR}=0.72,0.63,0.82, \mathrm{P}<0.001)$. Whereas, households time to fetch water from sources greater than 30 minutes were $30 \%(\mathrm{IRR}=0.70,0.61,0.79, \mathrm{P}<0.001)$ likely have $\mathrm{CHD}$ than those households fetch water less than 30 minutes from sources. Similarly, households no formal education were $44 \%(\operatorname{IRR}=0.56,0.51,0.75, \mathrm{P}<0.001)$ have developed $\mathrm{CHD}$ and also being primary education level were $38 \%$ at risk for $\mathrm{CHD}$ than those households with more than secondary education level(IRR: $0.62,0.53$, $0.73,<\mathrm{P}<0.001)$. However, respondents with the occupational status of farmer, merchant, student and housewife were more at risk of $\mathrm{CHD}$ than the government employee. 
Table 3

Multivariable analysis of the effect of the intervention on the incidence of CHD

\begin{tabular}{|c|c|c|c|c|c|}
\hline Variables & & $\operatorname{CIRR}(95 \% \mathrm{Cl})$ & $\begin{array}{l}\mathrm{P} \text { - } \\
\text { value }\end{array}$ & IRR(95\% Cl) & $\begin{array}{l}\mathrm{P} \text { - } \\
\text { value }\end{array}$ \\
\hline \multirow[t]{2}{*}{ Age of child in a month } & $<6$ & 1 & & & \\
\hline & $>6$ & $\begin{array}{l}0.16(0.15 \\
0.17)\end{array}$ & $<0.001$ & $\begin{array}{l}0.40(0.33 \\
0.50)\end{array}$ & $\begin{array}{l}< \\
0.001\end{array}$ \\
\hline \multirow[t]{2}{*}{$\begin{array}{l}\text { Availability of handwashing } \\
\text { facility }\end{array}$} & No & $\begin{array}{l}0.92(0.89 \\
0.95)\end{array}$ & $\begin{array}{l}< \\
0.001\end{array}$ & $\begin{array}{l}0.38(0.40 \\
0.42)\end{array}$ & $\begin{array}{l}< \\
0.001\end{array}$ \\
\hline & Yes & 1 & & & \\
\hline \multirow[t]{2}{*}{ Water consumption I/c/d } & $<20$ & $\begin{array}{l}0.96(0.93 \\
0.98)\end{array}$ & 0.001 & $\begin{array}{l}0.72(0.63 \\
0.82)\end{array}$ & $<.001$ \\
\hline & $>20$ & 1 & & & \\
\hline \multirow[t]{2}{*}{ Time to fetch water, minute } & $<30$ & $\begin{array}{l}0.98(0.96 \\
1.01)\end{array}$ & 0.25 & $\begin{array}{l}0.70(0.61 \\
0.79)\end{array}$ & $<0.001$ \\
\hline & $>30$ & 1 & & & \\
\hline \multirow[t]{2}{*}{ Handwashing a critical time } & No & $\begin{array}{l}0.94(0.92 \\
0.97)\end{array}$ & $<.001$ & $\begin{array}{l}0.79(0.70 \\
0.89)\end{array}$ & $<.001$ \\
\hline & Yes & 1 & & & \\
\hline \multicolumn{6}{|l|}{ Caregivers' education } \\
\hline Not formal & & $\begin{array}{l}0.89(0.86 \\
0.93)\end{array}$ & $<.001$ & $\begin{array}{l}0.56(0.51 \\
0.75)\end{array}$ & $<0.001$ \\
\hline Primary & & $\begin{array}{l}0.86(0.83 \\
0.90)\end{array}$ & $<.001$ & $0.62(0.53,0.73)$ & $<.001$ \\
\hline More than secondary level & & 1 & & & \\
\hline \multirow[t]{5}{*}{ Caregivers' occupational status } & Farmer & $0.16(0.15,0.18)$ & $<.001$ & $\begin{array}{l}0.38(0.32 \\
0.45)\end{array}$ & $<.001$ \\
\hline & Merchant & $\begin{array}{l}0.19(0.16 \\
0.23)\end{array}$ & $\hat{0}_{0.001}$ & $0.44(0.35,0.55)$ & $\begin{array}{l}< \\
0.001\end{array}$ \\
\hline & Student & $\begin{array}{l}0.16(0.14 \\
0.19)\end{array}$ & $<.001$ & $\begin{array}{l}0.38(0.31 \\
0.46)\end{array}$ & $<0.001$ \\
\hline & Housewife & $\begin{array}{l}0.13(0.13 \\
0.18)\end{array}$ & $<.001$ & $0.36(0.29,0.45)$ & $<.001$ \\
\hline & Employed & 1 & & & \\
\hline
\end{tabular}

Significant at p-value < 0.05 , CIRR: Crude Incidence rate ratio, IRR: Adjusted incidence rate ratio; $\mathrm{Cl}$ : Confidence interval 


\begin{tabular}{|c|c|c|c|c|c|}
\hline Variables & & CIRR (95\% Cl) & $\begin{array}{l}\mathrm{P} \text { - } \\
\text { value }\end{array}$ & $\operatorname{IRR}(95 \% \mathrm{Cl})$ & $\begin{array}{l}\mathrm{P}- \\
\text { value }\end{array}$ \\
\hline Family size & $>5$ & $0.15(0.11,22)$ & $\begin{array}{l}<.001 \\
0.01\end{array}$ & $0.82(0.68,1.00)$ & 0.056 \\
\hline
\end{tabular}

\section{Effects of intervention on CHD adjusted for effects of potential confounders}

Table 4 shows the results of Generalized Estimating Equation (GEE). Handwashing at critical times reduced incidence of CHD by $45 \%$ (IRR: $0.55,0.48,0.61, \mathrm{P}<0.001$ ) as compared with control groups. Similarly home based water treatment reduced incidence of $\mathrm{CHD}$ by $48 \%(\mathrm{IRR}=0.52,0.42,0.54, \mathrm{P}<0.001)$ as compared with control groups. Additionally, $60 \%$ (IRR $=0.40,0.36,0.46, \mathrm{P}<0.001$ ) of CHD have been reduced from households intervened with both interventions after adjusting potential confounders.

Table 4

Effects of intervention on incidence of CHD adjusted for effects of potential confounders

\begin{tabular}{|lllll|}
\hline Treatment & CIRR $(95 \%$ Cl) & P-value & IRR(95\% Cl) & P-value \\
\hline Hw & $0.99(0.96,1.02)$ & 0.595 & $0.55(0.48,0.61)$ & $<0.001$ \\
\hline HWT & $0.97(0.94 .99)$ & 0.043 & $0.48(0.42,0.54)$ & $<0.001$ \\
HW + HWT & $0.93(0.90,0.96)$ & $<0.001$ & $0.40(0.36,0.47)$ & $<0.001$ \\
\hline Control & 1 & & & \\
\hline $\begin{array}{l}\text { Significant at p-value < } 0.05, \text { HW: Hand washing, HWT: Home based water treatment, CIRR: Crude } \\
\text { incidence rate ratio, IRR: Adjusted incidence rate ratio; Cl: Confidence interval }\end{array}$ & \\
\hline
\end{tabular}

\section{Discussion}

This study revealed that there was a $45 \%$ (IRR: $0.55,0.48,0.61, \mathrm{P}<0.001$ ) reduction of CHDincidence among households intervened with handwashing with soap at critical times, which is constituent with previous findings reported a $42-47 \%$ reduction [31]. Another finding from Pakistan indicated a $53 \%$, diarrhea reduction [32] and a 33\% in Malawi [33] despite the level of reduction varied. The variation in reduction might be due to caregivers' handwashing practices and knowledge on diarrhea prevention. Moreover, different findings were reported different results across the RCT that might be due to adherence to intervention, earlier handwashing behavior, awareness on handwashing benefits and education level of the study participants that affect the intervention [34,35]. Insights suggest that preventive interventions 
tend to be adopted more slowly as benefits aredifficult to observe and users presumably discontinue treatment [36].

Evidences noticed that handwashing with soap eliminates transient potentially pathogenic organisms from the hands through the influences of microbial effectiveness[35], despite a complete change of handwashing behavior remains challenged [37]. Particularly handwashing before preparing food is a mostly imperative opportunity to avert CHD that appears to be a primary means of prevention where intervened households had a lower prevalence of $\operatorname{CHD}[38,39]$. Moreover, compared with controls, children in households with plain soap had a 53\% lower incidence of CHD in Karachi, Pakistan [40].

Our result suggested a $52 \%(\mathrm{IRR}=0.48,0.42,0.54, \mathrm{P}<0.001)$ reduction in $\mathrm{CHD}$ from home based water treatment households, which is comparable to the findings of a $48.0 \%$ reduction in Zambia [41], but higher than a $36 \%$ reduction in Dire Dawa, eastern Ethiopia [42]. It is evidenced that home based water treatment minimizes the risk of recontamination despite the improved water supply system [43-45]. Mostly, improved drinking water source alone is implausible to prevent CHD unless attention is also given to improving household water storage, and handling practices [46]. Besides, finding suggest a positive association between Escherichia coli counts in drinking water, (water as a vector for pathogens) and CHD [47]. More findings noted that 1.8 billion people globally use a source of drinking water suffered from faecal contamination. Moreover, drinking water is found to be a $41 \%$ more often contaminated in rural areas than in urban settings where a $53 \%$ contamination is most prevalent in Africa [48]. As a result, home based water treatment is the most cost effective among all water quality interventions that could be affordable for many of the households if they have access to the service [49] and a promising strategy to reach the under resourced areas with high CHD. Adopting household water treatment and safestorage systems, such as chlorination andfiltration, in both development and emergencies to support reductions in CHD.

Despite numerous studies demonstrated the effectiveness of home based water treatment and preventing diarrhea, the magnitude of $\mathrm{CHD}$ reduction were varied across the studies. For instance, a 23.0\% and 11\% reported from Ghana [50], 90.0\% in Liberia [51], 59.0\% in Haiti, Kenya, and Nicaragua [52], $58.0 \%$ in Kersa District, Ethiopia [53]. The reason might be due to adherence and compliance with treatment, water-handling practices to the extent of preventing recontamination [54]. Likewise, there might be the presence of chlorine-resistant parasitic protozoa such as oocysts of the Cryptosporidium species and cysts of Giardia lamblia [55]. In other parts, discontinuous use of the water treatment product due to the odor and taste of sodium hypochlorite may be a reason for these disparities in magnitude of the reduction [42]. Moreover, the correct and consistent usage of treated water relies almost exclusively on the consumer behavior [43]. In addition, households received the intervention might have been grateful and, out of courtesy, reported no or less CHD [56]. Mainly a 35\% baseline imbalance reported in quantifying bias in randomized controlled trials [57] that might be several reasons for variations of findings from unique intervention. 
Our finding indicated a $60 \%(\operatorname{IRR}=0.40,0.36,0.47, \mathrm{P}<0.001) \mathrm{CHD}$ reduction among households intervened with both handwashing with soap and home based water treatment. This study was constituent with the previous findings that the combination of home based water treatment and handwashing with soap have an additive effect, or synergistic effect of tackling multiple transmission routes simultaneously [58]. In addition, the magnitude of $\mathrm{CHD}$ reduction was consistent with the previous evaluations result [59]. In fact combining intervention could yield synergistic benefits, where coupling home based water treatment and handwashing intervention reduced recontamination of treated water through cleaner hands [60]. It is indicated that, with more-intensivepromotion of behavioral changes, the combined interventions would have hadgreater effects, as seen in smallscaletrials of handwashing and chlorinationof household water [38]. The highest magnitude of the protective effect in this study could be attributed to the high compliance of the intervention as observed during both scheduled and unannounced visits as compared with the previous findings.

In contradictory,findings revealed that there were no detectable interaction effects of the combined intervention, that does not seem to be additive [61]. The reason might be due to the slow implementation of intervention, lack of focus or lack of sufficient attention being given incombination and relied on single intervention, and courtesy bias, which might mask slight additive benefits [59].

Moreover, this study has noted some factors such as educational status sub-category no formal education level, WASH facilities like lack of handwashing facilities, less than 20 liter per capita water consumption, time to fetch water greater than 30 minutes from sources, and not washing hands at critical times were affected CHD. Several studies reported improved WASH practice reduced CHD in less developed countries [59]. But, now a day, there is increasing demands on water and sanitation everywhere, that highlighted the need for basic WASH in households as well as public places [62].

The limitation of this study was, it has not assessed both residual chlorine and microbial quality of drinking water that has an association between them in developing countries [43]. In addition, sub-group analysis within the intervention arms were not considered despite the observed reduction effects of both single and combined interventions.

\section{Conclusion}

This finding showed that handwashing with soap at critical times, home based water treatment, and both combinations have reduced CHD. Thus promoting this effective and promising result of intervention in rural communities would save many lives of children from diarrhea.

\section{Declarations}

\section{Authors' contribution}

AA, BTA, and BA participated in the research design, carried out data preparation and statistical analysis, interpreted the data. BA prepared the manuscript. AA, BTA, and BA offered major revisions. 


\section{Funding}

Not applicable

Availability of data and materials

Study materials including questionnaires and the data sets used are available on online.

Ethics approvals and consent to participate

Ethical clearance was obtained from Institutional Review Board (IRB) of Jimma University with references ID of IRB000343/2012, date 29/10/2012. Then the protocol was registered in the Pan African Clinical Trial Registry and PACTR202008856063947 unique identification number was obtained for this intervention.

\section{Consent for publication}

This manuscript does not contain any individual person's data in any form.

\section{Computing interest}

The authors have no competing interest

\section{References}

1. Bates SJ, Trostle J, Cevallos WT, Hubbard A, Joseph NS. Relating Diarrheal disease to social networks and the geographic configuration of communities in rural Ecuador. American Journal of Epidemiology. 2007;166:1088-95.

2. Budhathoki SS, Bhattachan M, Yadav AK, Upadhyaya P, Pokharel PK. Eco-social and behavioural determinants of diarrhoea in under-five children of Nepal: a framework analysis of the existing literature. Tropical Medicine and Health. 2016;:1-7. doi:10.1186/s41182-016-0006-9.

3. Green H, Bailey J, Schwarz L, Vanos J, Ebi K. Impact of heat on mortality and morbidity in low and middle income countries: A review of the epidemiological evidence and considerations for future research. Environmental Research. 2019;171 September 2018:80-91. doi:10.1016/j.envres.2019.01.010.

4. Ardkaew J, Tongkumchum P. Statistical modelling of childhood diarrhea statistical modelling of childhood diarrhea in northeastern Thailand. Southeast Asian J Trop Med Public Health. 2009;40:807-15.

5. Bessong PO, Odiyo JO, Musekene JN, Tessema A Spatial Distribution of Diarrhoea and Microbial Quality of Domestic Water during an Outbreak of Diarrhoea in the Tshikuwi Community in Venda, South Africa. J Health Popul Nutr. 2009;27:652-9. 
6. Cairncross S, Hunt AC, Boisson S, Bostoen K, Curtis V, Fung ICH. Water, sanitation and hygiene for the prevention of diarrhoea. International Journal of Epidemiology. 2010;:193-205.

7. Chaikaew N, Tripathi NK, Souris M. Exploring spatial patterns and hotspots of diarrhea in Chiang Mai,. International Journal of Health Geographics. 2009;10:8-36.

8. Jamison DT, Feachem RG, Makgoba MW, Bos ER, Baingana FK, Hofman KJ, et al. Disease and Mortality in Sub-Saharan Africa. 2006.

9. Shirley Karambu, Viviene Matiru Michael Kiptoo JO. Characterization and factors associated with diarrhoeal diseases caused by enteric bacterial pathogens among children aged five years and below attending Igembe District Hospital, Kenya. Pan Africa Medical Jourunal. 2013;:1-8.

10. Gleick PH. Dirty Water: Estimated Deaths from Water-Related Diseases 2000-2020. Pacific Institute Research. 2015;:1-12.

11. Dunn G. The Impact of Climate Variability and Conflict on Childhood Diarrhea and Malnutrition in West Africa. CUNY Academic WorksCUNY. 2016. http://academicworks.cuny.edu/gc_etds/.

12. Esrc R, Report A. Kandala,Ngianga-Bakwin(2007). Spatial variation of childhood diseases in Nigeria: Full Research Report ESRC End of Award Report, RES-000-22-1221. Swindon: ESRC. ESRC End of Award Repor. 2007;:1-23.

13. Asamoah A, Ameme DK, Sackey SO, Nyarko KM. Afari EA. Diarrhoea morbidity patterns in Central Region of Ghana. Pan Africa Medical Jourunal. 2016;73 Supp 1:1-5.

14. Pham-duc Nguyen-viet P, Zinsstag H, Tropical J, Hattendorf S, Cam J PD, et al. Diarrhoeal diseases among adult population in an agricultural community Hanam province, Vietnam, with high wastewater and excreta re-use. BMC Public Health 2014,. 2014;14:1471-2458.

15. Woldu W, Bitew BD, Gizaw Z. Socioeconomic factors associated with diarrheal diseases among under-five children of the nomadic population in northeast Ethiopia. Tropical Medicine and Health. 2016;::7-14.

16. Azage M, Kumie A, Worku A, Bagtzoglou AC. Childhood Diarrhea Exhibits Spatiotemporal Variation in Northwest Ethiopia: A SaTScan Spatial Statistical Analysis. PLoS ONE. 2015;2010:1-18.

17. Gebru T, Taha M, Kassahun W, Tekle Micheal. Risk factors of diarrhoeal disease in under-five children among health extension model and non-model families in Sheko district rural community, Southwest Ethiopia : comparative cross-sectional study. BMC Public Health. 2014;14:1-6.

18. Bartram JC Hygiene, Sanitation, and Water. Forgotten Foundations of Health. PLoS Med. 2021;:1000367.

19. Nicholson JA, Naeeni M, Hoptroff M, Matheson JR, Roberts AJ, Taylor D, et al. An investigation of the effects of a handwashingintervention on health outcomes and school absence using a randomised trial in Indian urban communities. 2014;19:284-92.

20. Curtis V, Cairncross S. Reviews Effect of washing hands with soap on diarrhoea risk in the community: a systematic review. 2003;3 May:275-81. 
21. Oloruntoba EO, Folarin TB, Ayede Al. Hygiene and sanitation risk factors of diarrhoeal disease among under-five children in Ibadan, Nigeria. African Health Sciences. 2014;14.

22. Alemayehu B, Teshome B, Kloos H, Ambelu A. Individual and community-level risk factors in under- fi ve children diarrhea among agro-ecological zones in southwestern Ethiopia. International Journal of Hygiene and Environmental Health. 2020;224:113447. doi:https://doi.org/10.1016/j.jijheh.2019.113447.

23. Painter J, Billhimer WL, Hoekstra RM, Children EM. Effect of Intensive Handwashing Promotion on Childhood Diarrhea in High-Risk Communities in Pakistan. Jourunal of American Medical Association. 2004;291:2547-54.

24. Darvesh N, Vaivada T. Water, sanitation and hygiene interventions for acute childhood diarrhea : a systematic review to provide estimates for the lives saved tool. BMC Public Health. 2017;17 November.

25. Bitew BD, Gete YK, Biks GA, Adafrie TT. The effect of SODIS water treatment intervention at the household level in reducing diarrheal incidence among children under 5 years of age: a cluster randomized controlled trial in Dabat district, northwest Ethiopia. BMC,Open Access. 2018;:1-15.

26. Abdiwahab Hashi, Abera Kumie JG. Handwashingwith soap and WASH educational intervention reduces under-five childhood diarrhoea incidence in Jigjiga District, Eastern Ethiopia: A communitybased cluster randomized controlled trial. Preventive Medicine. 2017;:1-23.

27. Clasen $\mathrm{T}$, Edmondson P. Sodium dichloroisocyanurate (NaDCC) tablets as an alternative to sodium hypochlorite for the routine treatment of drinking water at the household level. International Jourunal of Epidemiology. 2006;209:173-81.

28. Chakravarty I, Bhattacharya A, Das SK. Water, sanitation and hygiene : the unfinished agenda in the World Health Organization South-East Asia Region. WHO South-East Asian Jorunal of Public Health. 2017;6 September:22-6.

29. Bennett RH and S. Sample size calculation for cluster randomized trials. International Journal of Epidemiology. 2014;31:288-92.

30. Statacorp. Stata: Release 14.Statistical Software. College Station, TX: StataCorp LLC. 2015.

31. Curtis V, Cairncross S. Reviews Effect of washing hands with soap on diarrhoea risk in the community: a systematic review. THE LANCET Infectious Diseases. 2003;44:275-81.

32. Mubina Agboatwalla LS, John Painter M, Arshad Altaf D, Ward MBBSM, Billhimer L, Robert M M. Hoekstra P. Effect of Intensive Handwashing Promotion on Childhood Diarrhea in High-Risk Communities in Pakistan. The Journal of the American Medical Association 2004;291:2547-54.

33. Rissman L, Deavenport-saman A, Corden MH, Zipkin R, Espinoza J. handwashing educational intervention decreases incidence of respiratory and diarrheal illnesses in a rural Malawi orphanage. Global health promotion. 2020;0:1-9.

34. Ri E, Je E, Mm M, Ja C. Handwashingfor preventing diarrhoea (Review). TheCochrane Library. 2009.

35. Friedrich MND, Julian TR, Kappler A, Nhiwatiwa T, Mosler H American Journal of Infection Control Handwashing, but how? Microbial effectiveness of existing handwashing practices in high-density 
suburbs of Harare, Zimbabwe. American Journal of Infection Control. 2017;45:228-33.

36. Waddington $H$, Snilstveit $B$, White $H$. Water, sanitation and hygiene interventions to combat childhood diarrhoea in developing countries. Synthetic review. 2009;1 August.

37. Ri E, Je E, Arikpo D, Mm M, Ja C. Handwashingpromotion for preventing diarrhoea (Review). Cochrane library. 2015.

38. Black RE, Walker CF. Do Water, Sanitation, and Hygiene Interventions Prevent Childhood Diarrhea ? The Journal of Infectious Diseases. 2020;221:2019-21.

39. Grembi JA, Lin A, Karim A, Islam O, Miah R, Arnold BF. et al. Effect of Water, Sanitation, Handwashing, and Nutrition Interventions on Enteropathogens in Children 14 Months Old : A ClusterRandomized Controlled Trial in Rural Bangladesh. The Journal of Infectious Diseases. 2020; XX $X x x x: 1-14$.

40. Luby SP, Agboatwalla M, Feikin DR, Painter J, Ms WB, Altaf A, et al. Effect of handwashing on child health: a randomised controlled trial. Lancet. 2005;366:225-33.

41. Quick RE, Kimura A, Thevos A, Tembo M, Shamputa I, Hutwagner L, et al. Diarrhea prevention through household-level water disinfection and safe storage inZambia. Am J Trop Med Hyg,. 2002;66:584-9.

42. Solomon ET, Robele S, Kloos H, Mengistie B. Effect of household water treatment with chlorine on diarrhea among children under the age of five years in rural areas of Dire Dawa, eastern Ethiopia : a cluster randomized controlled trial. Infectious Diseases of Poverty. 2020;9:1-13.

43. Mosler LJ H. Effects of a behavior change campaign on household drinking water disinfection in the Lake Chad basin using the RANAS approach. Science of the Total Environment. 2018;619620:1599-607. doi:10.1016/j.scitotenv.2017.10.142.

44. Enger KS, Nelson KL, Rose JB, Eisenberg JNS. The joint effects of efficacy and compliance: A study of household water treatment effectiveness against childhood diarrhea. Water Research. 2012;47:1181-90. doi:10.1016/j.watres.2012.11.034.

45. Arnold BF, Jr JMC. Treating water with chlorine at point-of-use to improve water quality and reduce child diarrhea in developing countries: a systematic review and meta-analysis. Am J Trop Med Hyg, 2007;76:354-64.

46. Jensen PK, Jayasinghe G, Hoek W, Van Der, Cairncross S, Dalsgaard A. Is there an association between bacteriological drinking water quality and childhood diarrhoea in developing countries? Tropical Medicine and International Health. 2004;9:1210-5.

47. Brown JM, Proum S, Sobsey MD. Escherichia coli in household drinking water and diarrheal disease risk: evidence from Cambodia. Water Science \& Technology. 2008;:757-64.

48. Bain R, Cronk R, Hossain R, Bonjour S, Onda K, Wright J, et al. Global assessment of exposure to faecal contamination through drinking water based on a systematic review. Tropical Medicine and International Health volume. 2014;19:917-27.

49. Clasen, Kt A, Sinclair D, Boisson S, Peletz R, Hh C. et al. Interventions to improve water quality for preventing diarrhoea (Review). Cochrane Database of Systematic Reviews Interventions. 2015. 
50. Kang CS, Tuffuor D, Lee B, Cho G J. The Effect of Improved Water Supply on Diarrhea Prevalence of Children under Five in the Volta Region of Ghana: A Cluster-Randomized Controlled Trial. Int $\mathrm{J}$ Environ Res Public Health. 2015; February 2014:12127-43.

51. Doocy S, Burnham G. Point-of-use water treatment and diarrhoea reduction in the emergency context: an effectiveness trial in Liberia. Tropical Medicine and International Health. 2006;11:1542-52.

52. Napotnik MAL, Rayner JA, Mendoza JS, Mitro A, Norville B J, et al. Evaluation of consistent use, barriers to use, and microbiological effectiveness of three prototype household water treatment technologies in Haiti, Kenya, and Nicaragua. Science of the Total Environment. 2020;718:134685. doi:10.1016/j.scitotenv.2019.134685.

53. Eshete N, Id S, Gari SR, Hailu AB, Alemu M. Association between microbial water quality, sanitation and hygiene practices and childhood diarrhea in Kersa and Omo Nada districts of Jimma Zone, Ethiopia. PLoS ONE. 2020;396:1-17. doi:10.1371/journal.pone.0229303.

54. Rosa G, Clasen T. Consistency of Use and Effectiveness of Household Water Treatment among Indian Households Claiming to Treat Their Water. Am J Trop Med Hyg,. 2017;97:259-70.

55. Omarova A, Tussupova K, Berndtsson R, Kalishev M. Protozoan Parasites in Drinking Water. A System Approach for Improved Water, Sanitation and Hygiene in Developing Countries. International Journal of Environmental Research and Public Health Review. 2018;15:1-18.

56. Wood L, Egger M, Gluud LL, Ju P, Gluud C. Empirical evidence of bias in treatment effect estimates in. BMJ RESEARCH. 2001; November.

57. Hartling L, Hamm MP, Fernandes RM, Dryden DM, Vandermeer B. Quantifying Bias in Randomized Controlled Trials in Child Health: A Meta-Epidemiological Study. PLoS ONE. 2014;9.

58. Briceño B, Coville A, Paul Gertler, Sebastian Martinez. Are there synergies from combining hygiene and sanitation promotion campaigns: Evidence from a large-scale cluster- randomized trial in rural Tanzania. PLoS ONE. 2017;:1-19.

59. Fewtrell L, Kaufmann RB, Kay D, Enanoria W, Haller L, Jr JMC. WASH interventions to reduce diarrhoea in less developed countries. Lancet Infection Diseases. 2005;5 January:42-52.

60. Mertens EA, Arnold A, Benjamin-chung BF, Hubbard J, Ahmed AE MA, et al. Effects of Single and Combined Water, Sanitation and Handwashing Interventions on Fecal Contamination in the Domestic Environment: A Cluster-Randomized Controlled Trial in Rural Bangladesh. Environ Sci Technol. 2018.

61. Esrey SA, Potash JB, Roberts L, Shiff C. Reviews / Analyses Effects of improved water supply and sanitation on. 1991.

62. Jiménez A. Water \& Sanitation response to Covid-19. UNICEF. 2020;:1-12.

\section{Figures}




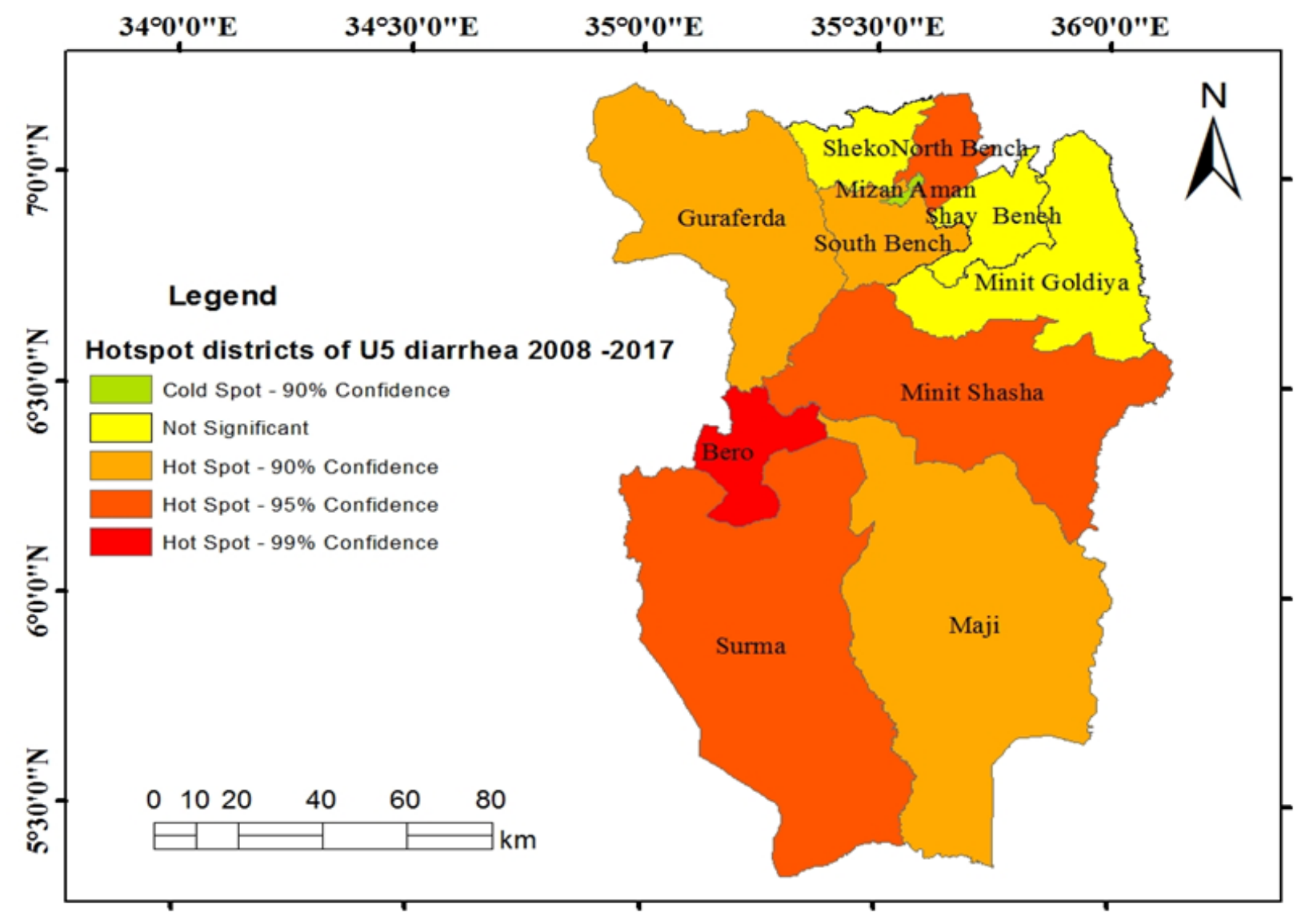

Figure 1

Identified hotspot areas of CHD in Bench Maji zone, southwestern Ethiopia (Source: Alemayehu et al., 2020) 


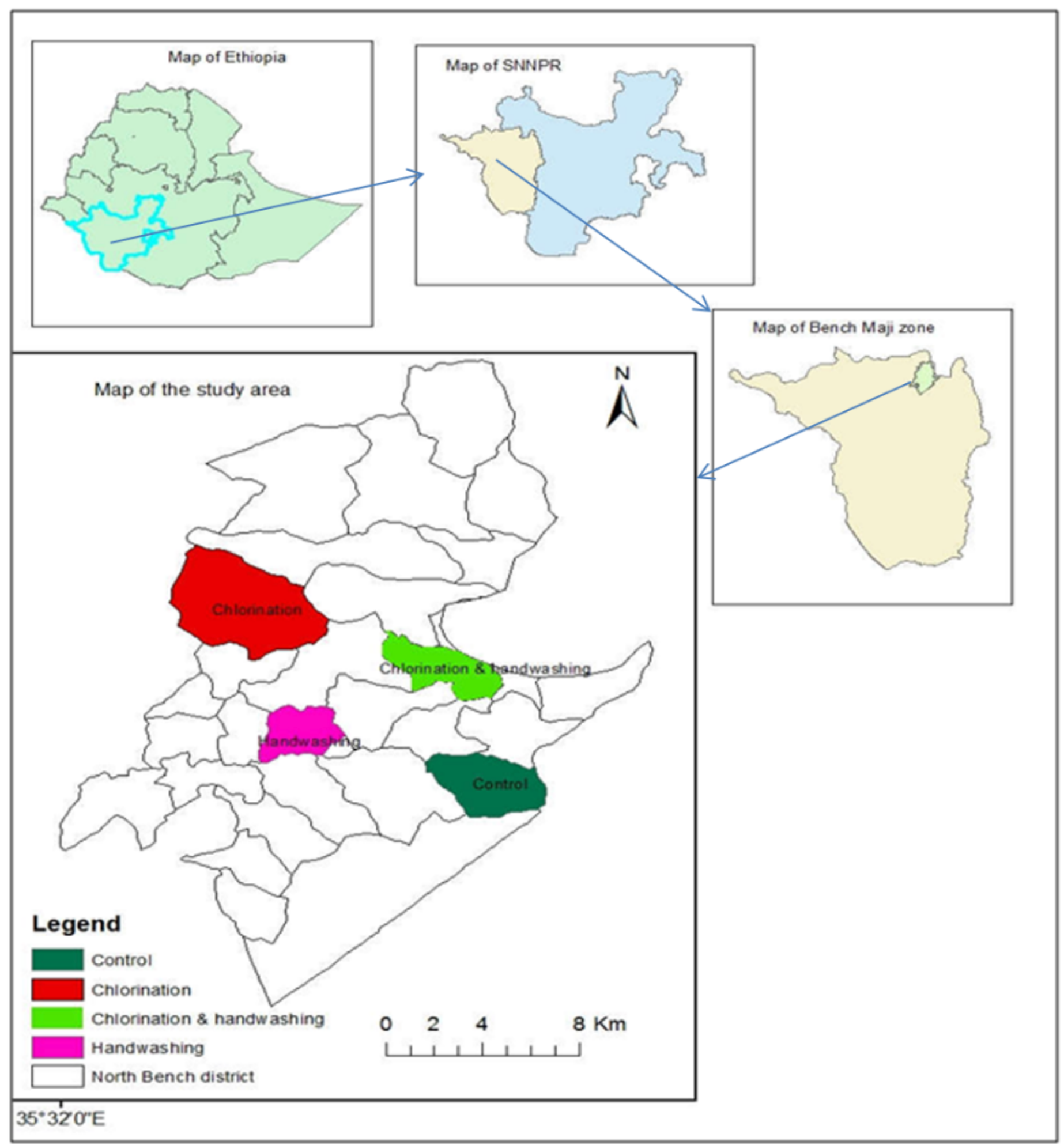

Figure 2

Map showing the location of the study area 


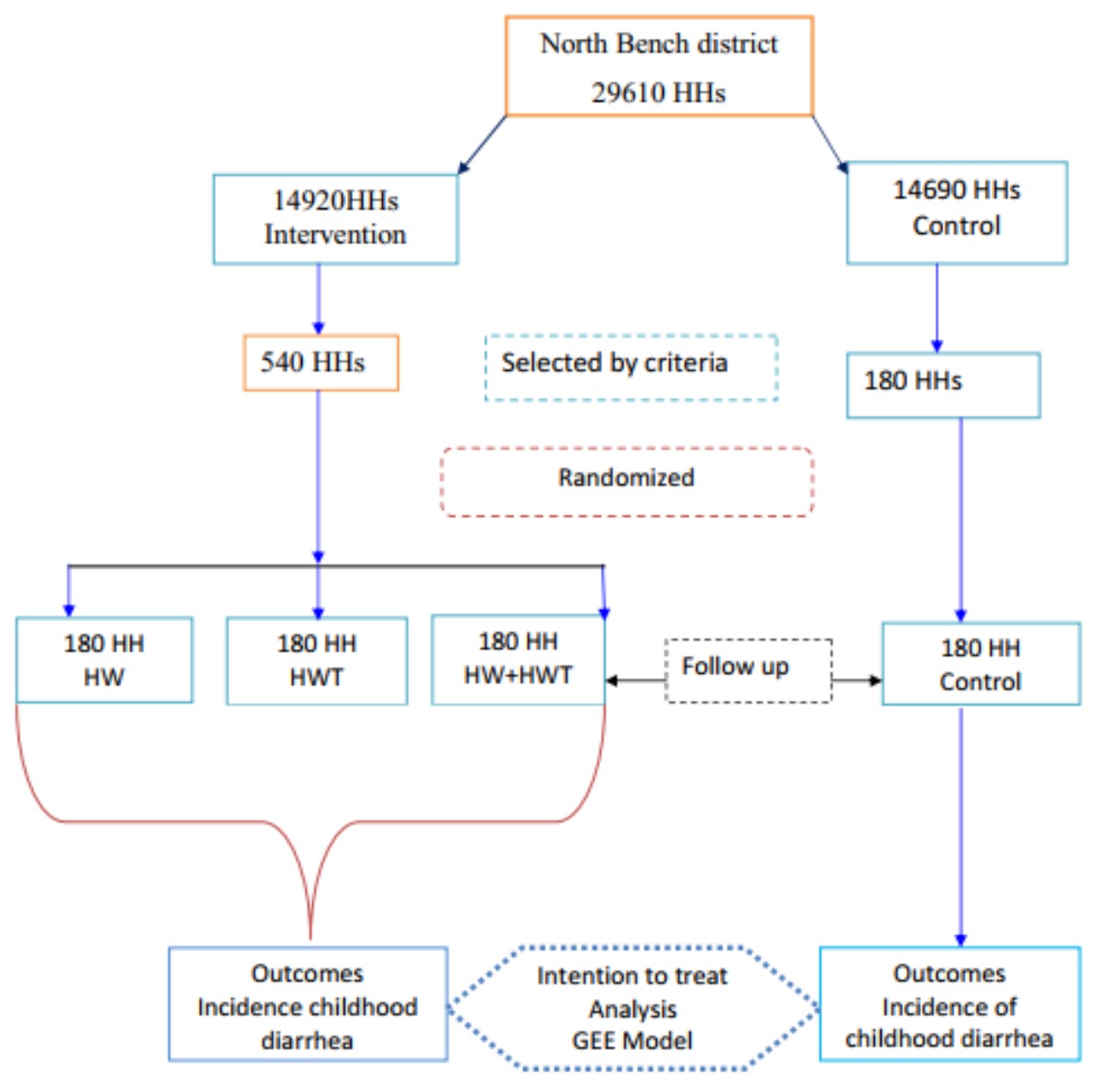

Figure 3

Randomization process. HW: Hand washing, HWT: Home-based water treatment 


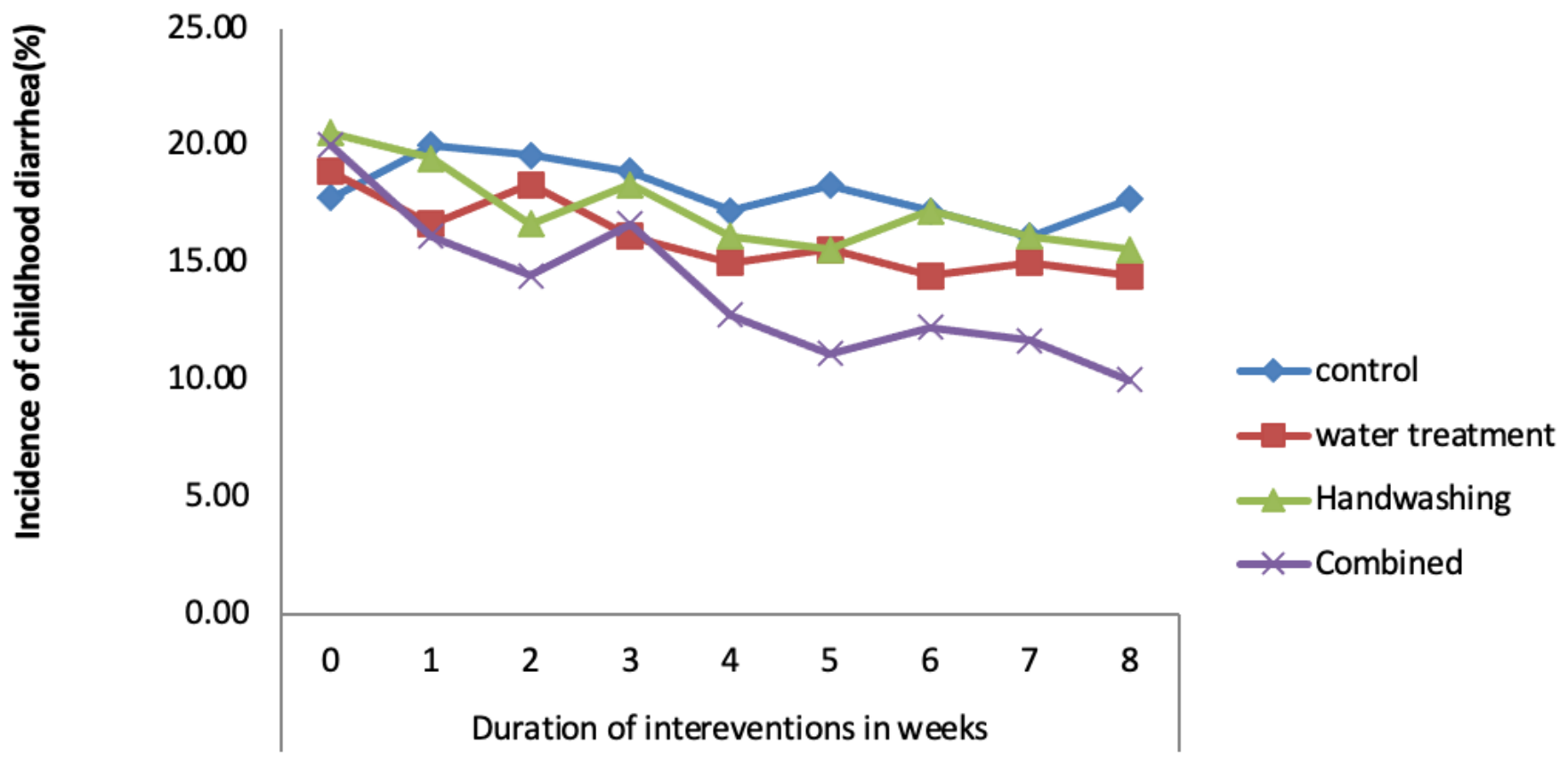

Figure 4

Bi-weekly incidence of CHD versus weeks of observation of interventions

\section{Supplementary Files}

This is a list of supplementary files associated with this preprint. Click to download.

- BaselinedataBA.sav

- LongitudinaldatasediarrheaincidenceRCT.csvBA.csv

- ProtocolBA.docx 